\title{
Perancangan Sistem Informasi Perpustakaan pada Sekolah Eka Wijaya Berbasis Java
}

\author{
Mirna Miranda $^{1}$, Puput Irfansyah ${ }^{2}$, Erlando Doni Sirait ${ }^{3}$ \\ ${ }^{123}$ Program Studi Informatika Universitas Indraprasta PGRI Jakarta, Indonesia \\ Jl. Raya Tengah No. 80 Gedong, Kec. Ps. Rebo, Jakarta, Indonesia \\ e-mail: '1miranda.mirna17@gmail.com, ${ }^{2}$ irfandot@gmail.com, ${ }^{3}$ erlandodoni19@gmail.com
}

Submitted Date: November $06^{\text {th }}, 2020$

Reviewed Date: December $30^{\text {th }}, 2020$

Revised Date: January $16^{\text {th }}, 2021$

Accepted Date: June $14^{\text {th }}, 2021$

\begin{abstract}
Libraries have books that are references or sources of knowledge that they want to know, sometimes even this information cannot be searched on the internet so that the number of books in the library is very large. With so many books in the library, of course, a system is needed to organize all the books so that these books can be recorded properly so as to reduce the risk of book census errors such as the number of books, borrowers, categories and also the delivery of more detailed information for books. because of that, it takes an information system design for a library. In designing an information system, a concept or research method is needed that can minimize mistakes in the flow of application creation, the method used is Waterfall modeling of this method, an application is made using Java Netbeans with MySQL database. By using this method, the application can run according to the flow, namely the details of the books in the library are in harmony with the actual situation and a decrease in data errors resulting in the loss of some information in the library such as the number of books, the number of borrowings, book details and so on. It makes it easier for users to find the information they want.
\end{abstract}

Keywords: Design; System; Library; Java; MySQL

Abstrak

Perpustakaan memiliki buku-buku yang menjadi refrensi atau sumber pengetahuan yang ingin diketahui, bahkan terkadang informasi tersebut tidak dapat dicari di internet sehingga jumlah buku yang terdapat di perpustakaan sangat banyak. Dengan banyaknya buku-buku di perpustakaan tentu saja dibutuhkan sistem untuk mengatur semua buku-buku agar buku-buku tersebut dapat didata dengan baik sehingga menurunkan resiko kesalahan pendataan buku seperti jumlah buku, peminjam, kategori dan juga penyampaian informasi yang lebih detail untuk buku-buku tersebut, karena itulah, dibutuhkannya suatu perancangan sistem informasi untuk suatu perpustakaan. Dalam merancang suatu sistem informasi dibutuhkan konsep atau metode penelitian yang dapat meminimalisir kekeliruan dalam alur penciptaan aplikasi, metode yang digunakan adalah pemodelan Waterfall dari metode ini, dibuatlah aplikasi menggunakan Java Netbeans yang ber-database MySQL. Dengan menggunakan metode ini, aplikasi dapat berjalan sesuai alurnya yaitu detail buku di perpuskataan menjadi selaras dengan keadaan sebenarnya serta menurunnya kekeliruan data yang mengakibatkan hilangnya beberapa informasi di perpustakaan seperti jumlah buku, jumlah peminjaman, detail buku dan lain sebagainya. Pengguna menjadi lebih termudahkan dalan mencari informasi yang diinginkan.

Kata kunci : Perancangan, Sistem, Perpustakaan, Java, MySQL

\section{Pendahuluan}

Sederhananya, sistem dapat didefinisikan sebagai sekumpulan atau kumpulan elemen, komponen, atau variabel yang dikonfigurasi, berinteraksi, dan bergantung satu sama lain.
Informasi itu sendiri, di sisi lain, adalah data yang diklasifikasikan, diproses, atau diinterpretasikan untuk digunakan dalam proses pengambilan keputusan. Dalam contoh, masukkan sistem. Sebuah "program" dalam perangkat sistem 
komputer memasuki pemeliharaan input yang digunakan untuk mengoperasikan komputer. Di sisi lain, "data" adalah sinyal masukan yang diproses sebagai informasi. Oleh karena itu, sistem informasi merupakan gabungan antara teknologi informasi dan aktivitas masyarakat yang menggunakan teknologi tersebut untuk mendukung manajemen operasi.

Di dalam sistem informasi sendiri dibutuhkan perancangan. Perancangan adalah rencana atau gambar yang dibuat untuk menunjukkan tampilan dan fungsi atau cara kerja berdasarkan beberapa elemen yang terpisah ke pada satu kesatuan yang utuh dan berfungsi menjadi perancangan sistem bisa didesain pada bentuk bagan alir sistem (system flowchart), yang adalah indera bentuk grafik yg bisa dipakai buat menerangkan urutan-urutan proses berdasarkan sistem.

Ketika perancangan sistem informasi sendiri telah ada, selanjutnya adalah melihat masalah apa yang membutuhkan perancangan di dalam sistem informasinya, dan perpustakaan adalah salah satunya.

Perpustakaan merupakan tempat yang paling sering orang kunjungi dalam mencari informasi yang mereka butuhkan, terutama anakanak sekolah yang diharuskan untuk lebih banyak membaca buku dibandingkan bermain gawai, bahkan terkadang informasi tersebut tidak dapat dicari di internet dengan mudah, karena itu dibutuhkan buku-buku yang menjadi refrensi atau sumber pengetahuan yang ingin diketahui. Dengan banyaknya buku-buku yang berada di perpustakaan tentu saja dibutuhkan sistem untuk mengatur semua buku-buku tersebut agar buku tersebut dapat didata dengan baik sehingga menurunkan resiko kesalahan pendataan buku seperti jumlah buku, peminjam, kategori dan juga penyampaian informasi yang lebih detail untuk buku-buku tersebut, karena itulah, dibutuhkannya suatu perancangan sistem informasi untuk suatu perpustakaan.

Selain dalam pendataan, dibutuhkan juga keteraturan dalam ketersediaan bangku di dalam perpustakaan karena kekhawatiran ketika seseorang sungguh-sungguh ingin mencari informasi namun tidak tersedianya tempat untuk dia pakai dalam membaca dan tempat itu justru dipakai orang lain yang hanya untuk "numpang" duduk saja di perpustakaan.

Semakin ditelaah, dibutuhkan keteraturan didalam perpustakaan agar berjalan sesuai dengan yang seharusnya karena itu dibutuhkan perancangan sistem informasi.

\section{Metodologi Penelitian}

Konsep atau metode penelitian yang digunakan di penelitian ini adalah pemodelan Waterfall. Waterfall adalah proses manajemen proyek yang berurutan dan linier, ini terdiri dari beberapa fase terpisah, tidak ada fase yang dimulai hingga fase sebelumnya selesai, dan penyelesaian setiap fase adalah terminal, Waterfall tidak memungkinkan anda untuk kembali ke fase sebelumnya, satu-satunya cara untuk meninjau kembali suatu fase adalah memulai kembali dari fase pertama. Lucidchart Content Team (2018).

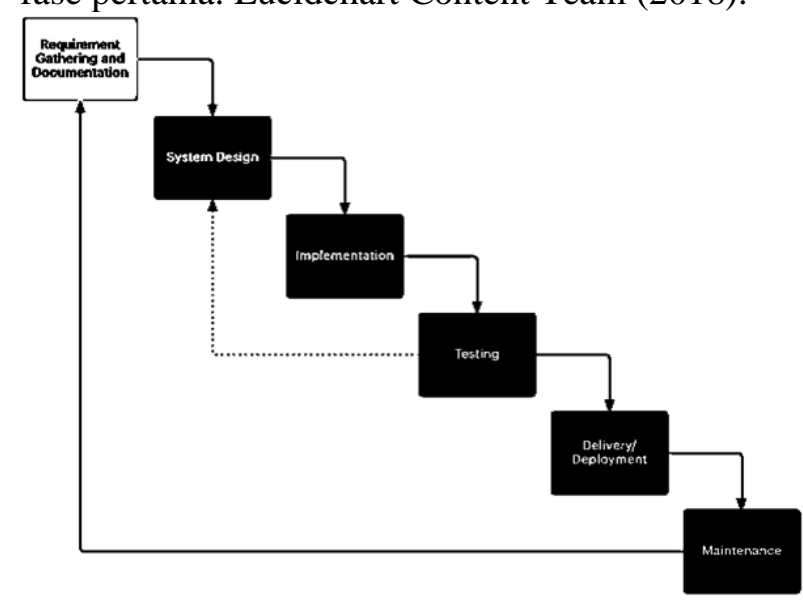

Gambar 1 Pemodelan Waterfall (Pressman, 2015)

Adapun tahapan-tahapan dari metode Waterfall adalah sebagai berikut:

1. Pengumpulan dan Dokumentasi Kebutuhan

Pada tahap ini, harus mengumpulkan informasi lengkap tentang apa yang dibutuhkan penelitian ini. Informasi dapat dikumpulkan dengan berbagai cara mulai dari wawancara, kuesioner hinggga curah pendapat interaktif. Dibagian ini peneliti membutuhkan data buku, data bangku, data anggota, data peminjaman, data pengembalian serta pendapat para murid.

2. Desain Sistem

Dengan menggunakan persyaratan yang ditetapkan, peneliti merancang sistem. Tidak ada pengkodean yang dilakukan selama fase ini, tetapi dapat menetapkan spesifikasi seperti bahasa pemrograman atau persyaratan perangkat keras. Dibagian ini peneliti merancang sistem agar tidak adanya kekeliruan di kemudian hari.

3. Implementasi 
Pengkodean berlangsung selama fase ini. Peneliti mengambil informasi dari tahap sebelumnya dan membuat produk fungsional. Biasanya menerapkan kode dalam potongan-potongan kecil, yang terintegrasi pada akhir fase ini atau awal berikutnya.

4. Pengujian

Setelah semua pengkodean selesai, pengujian aplikasi dapat dimulai. Pengguna menemukan dan melaporkan masalah apapun. Jika masalah serius muncul seperti aplikasi tidak dapat berjalan maka peneliti akan kembali ke tahap pertama untuk evaluasi ulang.

5. Pengiriman / Penyebaran

Dalam fase ini, aplikasi sudah dapat berjalan sesuai tujuan yang diharapkan maka aplikasi akan diterapkan.

6. Pemeliharaan

Setelah berhasil diterapkan, sesekali diperlukan pembaruan untuk mencegah serta mengatasi masalah yang dating di kemudian hari.

Berikut adalah metode pengumpulan data yang dilakukan oleh penulis Metode pengumpulan data yang digunakan di penelitian ini adalah:

1. Observasi

Pengumpulan data dilakukan langsung di Sekolah Eka Wijaya, tidak hanya mengumpulkan data saja tetapi juga memperhatikan berbagai sikap dan fenomena yang terjadi dari para siswa dan petugas perpustakaan sebagai bahan untuk menganalisa kebutuhan.

2. Wawancara

Peneliti memberi beberapa pertanyaan langsung kepada para siswa maupun petugas perpustakaan untuk memastikan kebutuhan di Sekolah Eka Wijaya.

3. Dokumentasi

Peneliti melakukan pengumpulan data dengan cara melihat kemudian mencatat data yang terdapat di perpustakaan Sekolah Eka Wijaya.

4. Metode Kepustakaan

Peneliti membaca dan mempelajari dari buku serta internet terkait masalah yang terjadi di penelitian ini.

\section{Hasil dan Pembahasan}

Sistem peminjaman buku yang diterapkan masih manual yaitu dengan menumpuk tanggung jawab kepada petugas perpustakaan, mulai dari pencatatan koleksi buku, penataan buku, peminjaman buku, pengembalian buku, serta penyusunan laporan di perpustakaan. Hanya terdapat 1 petugas di perputakaan sehingga tugas ini menjadi lebih berat. Oleh karena ini dibutuhkan proses bisnis sebagai berikut:

1. Proses Pendataan Siswa

a. Setiap siswa/i wajib membawa id card mereka jika ingin memasuki perpustakaan.

b. Setiap siswa/i mendaftarkan diri mereka di aplikasi yang disediakan.

2. Proses Peminjaman Buku

a. Siswa/i hanya boleh meminjam paling banyak 3 buku, sedangkan buku yang bersifat laporan, karya tulis ilmiah dan sejenisnya tidak boleh dibawa pulang.

b. Siswa/i yang tidak memilih bangku tidak diizinkan untuk duduk di sembarang tempat di Perpustakaan.

c. Siswa/i wajib membawa serta id card mereka saat ingin meminjam buku.

d. Jika buku dibawa pulang, buku harus dikembalikan selambat-lambatnya 7 hari dari tanggal peminjaman buku, jika tidak akan dikenakan denda.

3. Proses Pemilihan Bangku Duduk

a. 1 anggota hanya dapat memilih 1 bangku, tidak boleh membooking untuk orang lain.

b. Jika ingin membawa pulang buku yang sedang dibaca masukkan data peminjaman di aplikasi yang disediakan.

4. Proses Pengembalian \& Denda Buku

a. Buku harus dikembalikan selambatlambatnya 7 hari dari tanggal peminjaman buku.

b. Jika buku dipinjam melebihi dari waktu pemulangan yang ditentukan (7 hari) maka perharinya akan dihitung Rp. 500,/buku/hari.

c. Jika memulangkan buku kurang atau pas 7 hari setelah tanggal peminjaman maka tidak dikenakan biaya apapun.

d. Kembalikan buku ke petugas perpusakaan dengan membawa buku yang dipinjam beserta id car setelah menghitung denda pada aplikasi.

5. Proses Laporan

Print out yang ada harus dengan persetujuan pertugas perpustakaan.

Serta dekomposisi seperti ini: 


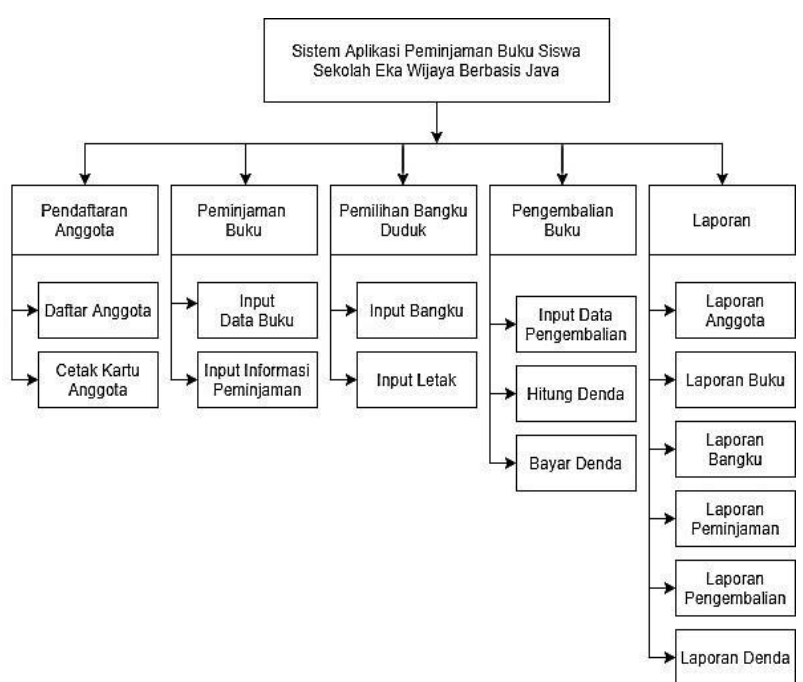

Gambar 2 Dekomposisi Sistem

\subsection{Diagram Konteks}

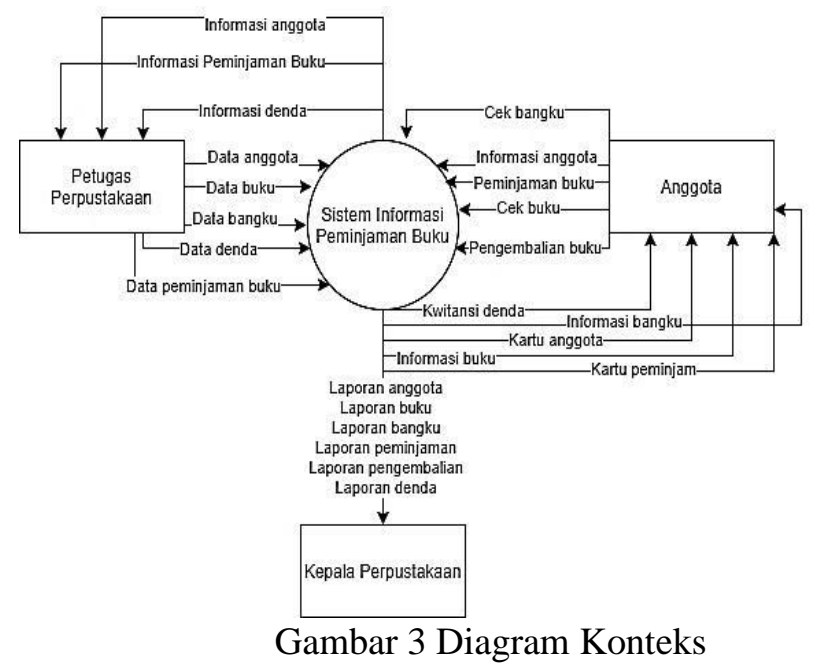

\subsection{Diagram Nol}




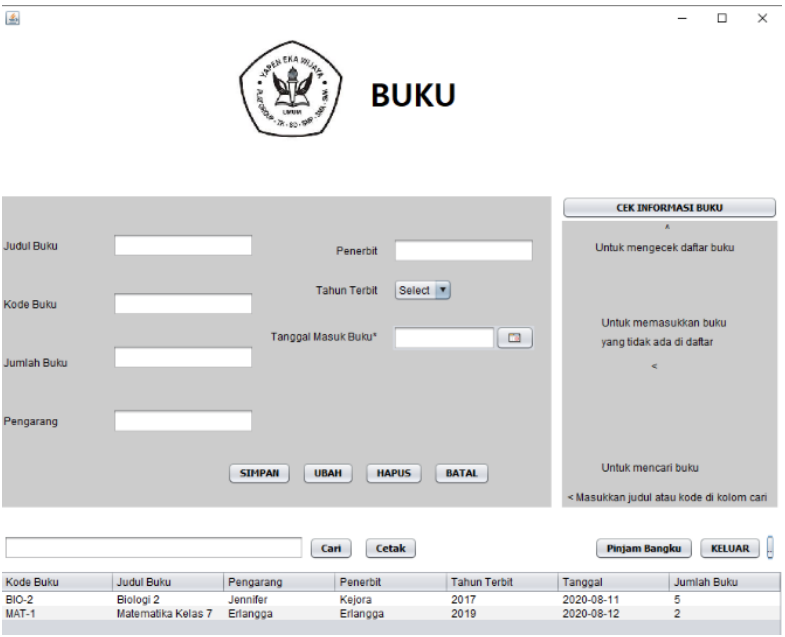

Gambar 5 Tampilan Form Buku

c. Tampilan Bangku untuk mengisi data bangku yang ingin dimasukkan atau dipinjam.

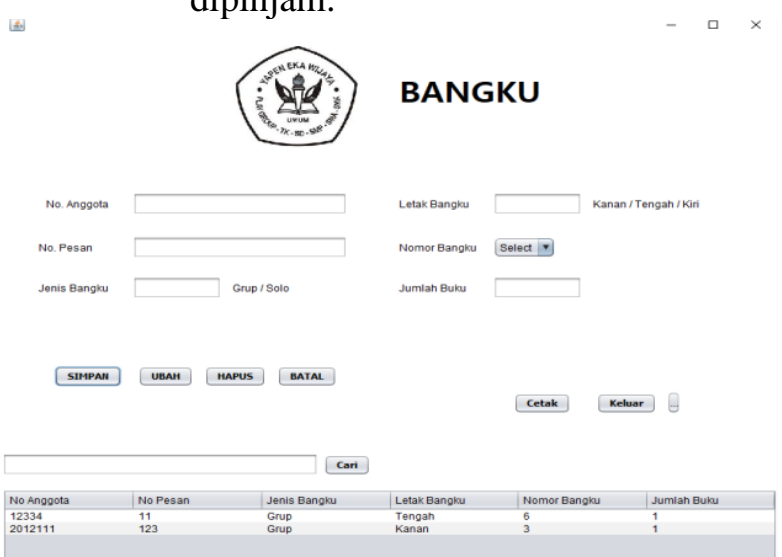

Gambar 6 Tampilan Form Bangku

d. Tampilan Peminjaman untuk mengisi atau mengecek data peminjaman yang ingin dilihat.

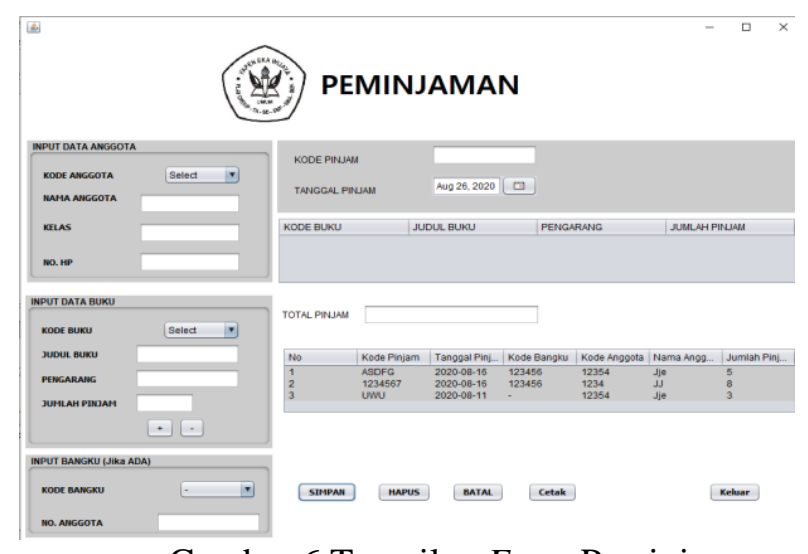

Gambar 6 Tampilan Form Peminjaman e. Tampilan Pengembalian untuk mengisi atau mengecek data peminjaman untuk melakukan penembalian untuk buku yang dipinjam ada denda atau tidaknya.

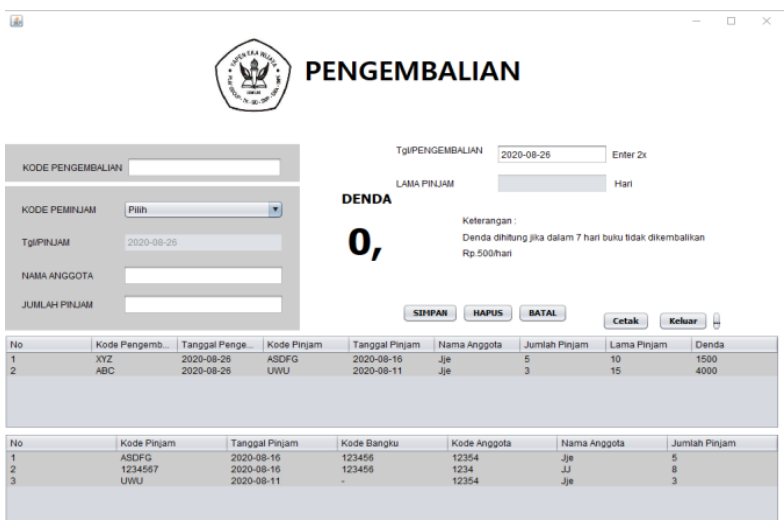

Gambar 7 Tampilan Form Pengembalian

f. Tampilan Laporan untuk mengecek data peminjaman yang telah dilakukan selama ini.

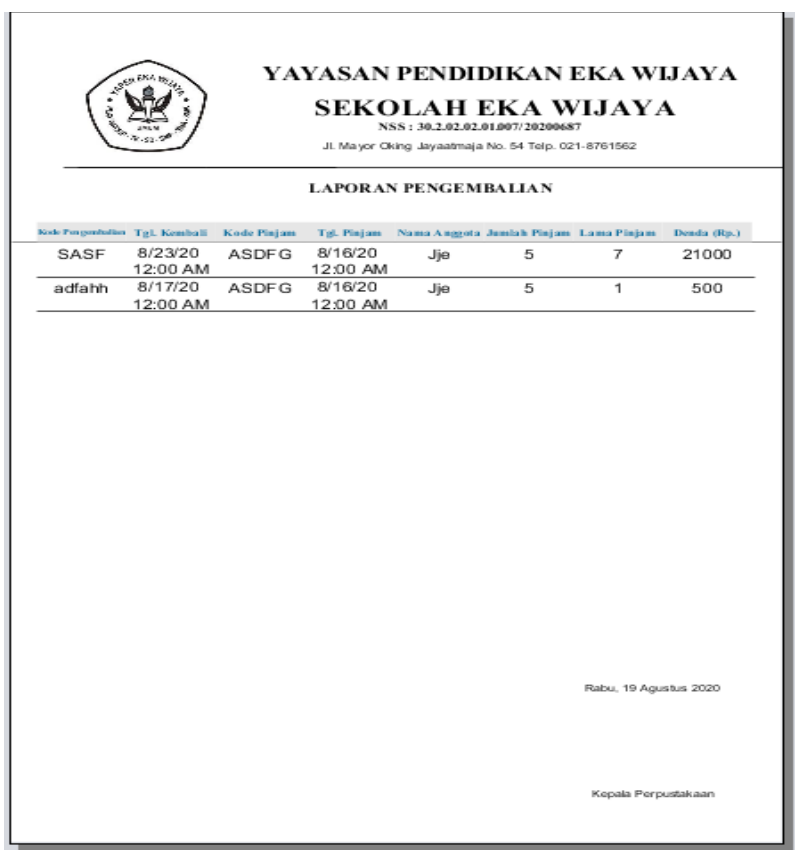

Gambar 8 Tampilan Form Laporan Pengembalian

\subsection{Black Box Testing}

Setelah melakukan perancangan, maka selanjutnya dilakukan langkah pengujian menggunakan black box testing. Black box testing adalah metode pengujian perangkat lunak yang memeriksa fungsionalitas aplikasi tanpa mengintip ke dalam struktur atau cara kerjanya. Berikut ini langkah-langkah dalam pengecekannya: 
a. Pengujian Black Block Testing Pada Form Login
Pada proses ini diuji segala fungsi yang terdapat di form login satu per satu untuk mengecek adanya kekeliruan atau tidak.

Tabel 1 Pengujian Blackbox Form Login

\begin{tabular}{|r|l|l|c|}
\hline No & \multicolumn{1}{|c|}{ Skenario Pengujian } & \multicolumn{1}{|c|}{ Hasil yang Diterapkan } & Kesimpulan \\
\hline 1 & $\begin{array}{l}\text { Menggunakan nama Nama Pengguna } \\
\text { dan Kata Sandi dengan benar, lalu klik } \\
\text { tombol "Masuk" }\end{array}$ & $\begin{array}{l}\text { Sistem akan mengakses Masuk dan } \\
\text { menampilkan pesan "Connection } \\
\text { Success" dan masuk ke Menu Utama }\end{array}$ & Sesuai \\
\hline 2 & $\begin{array}{l}\text { Menggunakan Nama Pengguna dan Kata } \\
\text { Sandi dengan salah, lalu klik tombol } \\
\text { "Masuk" }\end{array}$ & $\begin{array}{l}\text { Sistem akan menolak akses Masuk dan } \\
\text { menampilkan pesan "Nama } \\
\text { Pengguna/Kata Sandi Salah!" }\end{array}$ & Sesuai \\
\hline 3 & $\begin{array}{l}\text { Hanya mengisi Nama Pengguna dan } \\
\text { mengosongkan Kata Sandi, lalu klik } \\
\text { tombol "Masuk" }\end{array}$ & $\begin{array}{l}\text { Sistem akan menolak akses Masuk dan } \\
\text { menampilkan pesan "Nama } \\
\text { Pengguna/Kata Sandi Salah!" Sesuai }\end{array}$ & \\
\hline 4 & $\begin{array}{l}\text { Hanya mengisi Kata Sandi dan } \\
\text { mengosongkan Nama Pengguna, lalu } \\
\text { klik tombol "Masuk" }\end{array}$ & $\begin{array}{l}\text { Sistem akan menolak akses Masuk dan } \\
\text { menampilkan pesan "Nama } \\
\text { Pengguna/Kata Sandi Salah!" "Na }\end{array}$ & Sesuai \\
\hline
\end{tabular}

b. Pengujian Black Block Testing Pada Form Data Buku

Pada proses ini diuji segala fungsi masukan dan keluaran yang terdapat di form data buku satu per satu untuk mengecek adanya kekeliruan atau tidak.

Tabel 2 Pengujian Blackbox Form Data Buku

\begin{tabular}{|c|l|l|c|}
\hline No & \multicolumn{1}{|c|}{ Skenario Pengujian } & \multicolumn{1}{|c|}{ Hasil yang Diterapkan } & Kesimpulan \\
\hline 1 & $\begin{array}{l}\text { Input form } \\
\text { Data buku, } \\
\text { lalu klik "SIMPAN" }\end{array}$ & $\begin{array}{l}\text { Sistem tidak akan dapat menyelesaikan } \\
\text { prosesnya apabila tanggal tidak dipilih, dan } \\
\text { akan menampilkan pesan "Data Tidak } \\
\text { Tersimpan" namun apabila tanggal terisi } \\
\text { walaupun ada data kolom yang kosong "Data } \\
\text { Berhasil Disimpan" }\end{array}$ & Sesuai \\
\hline 2 & $\begin{array}{l}\text { Masukkan } \\
\text { salah satu isi dari informasi } \\
\text { buku di form kemudian isi } \\
\text { kembali data dan klik "UBAH" } \\
\text { untuk mengubah data }\end{array}$ & $\begin{array}{l}\text { Sistem dapat menyimpan data walaupun ada } \\
\text { kolom yang tetap kosong dan menampilkan } \\
\text { kosong total maka akan menampilkan "Data } \\
\text { Tidak Diperbaharui" }\end{array}$ & Sesuai \\
\hline 3 & $\begin{array}{l}\text { Masukkan } \\
\text { salah satu isi } \\
\text { dari informasi buku di form, } \\
\text { lalu klik tombol "HAPUS" }\end{array}$ & $\begin{array}{l}\text { Sistem akan memberikan pesan "Data Berhasil } \\
\text { Dihapus" }\end{array}$ & Sesuai \\
\hline 4 & $\begin{array}{l}\text { Klik tombol "BATAL" pada } \\
\text { form data Buku }\end{array}$ & Sistem akan menghapus semua isi di di kolom. & Sesuai \\
\hline 5 & $\begin{array}{l}\text { Masukkan Judul Buku atau } \\
\text { Kode pada kolom cari, lalu klik } \\
\text { "Cari" untuk mencari data }\end{array}$ & $\begin{array}{l}\text { Sistem akan menampilkan data yang dicari di } \\
\text { tabel, namun jika data tidak ada maka sistem } \\
\text { akan memberi pesan "Data yang Anda cari } \\
\text { Tidak dapat Ditemukan" }\end{array}$ & Sesuai \\
\hline 6 & $\begin{array}{l}\text { Klik tombol "Keluar" pada form } \\
\text { data Buku }\end{array}$ & Sistem akan kembali ke menu utama. & Sesuai \\
\hline
\end{tabular}


c. Pengujian Black Block Testing Pada Form Data Bangku

Pada proses ini diuji segala fungsi masukan dan keluaran yang terdapat di form data bangku satu per satu untuk mengecek adanya kekeliruan atau tidak.

Tabel 3 Pengujian Blackbox Form Data Bangku

\begin{tabular}{|c|l|l|c|}
\hline Jo & \multicolumn{1}{|c|}{ Skenario Pengujian } & \multicolumn{1}{|c|}{ Hasil yang Diterapkan } & Kesimpulan \\
\hline 1 & $\begin{array}{l}\text { Input form Data Bangku, } \\
\text { lalu klik "SIMPAN" }\end{array}$ & $\begin{array}{l}\text { Sistem tetap dapat menyimpan data walaupun } \\
\text { hanya 1 kolom yang terisi dan menampilkan } \\
\text { "Data Berhasil Disimpan". Tetapi jika form } \\
\text { kosong total maka akan menampilkan "Data } \\
\text { Tidak Tersimpan" }\end{array}$ & Sesuai \\
\hline 2 & $\begin{array}{l}\text { Masukkan salah satu isi dari } \\
\text { informasi bangku di form } \\
\text { kemudian isi kembali data } \\
\text { dan klik "UBAH" untuk } \\
\text { mengubah data }\end{array}$ & $\begin{array}{l}\text { kolom yang tetap kosong dan menampilkan "Data } \\
\text { Berhasil Diperbaharui". Tetapi jika form kosong } \\
\text { total maka akan menampilkan "Data Tidak } \\
\text { Diperbaharui" }\end{array}$ & Sesuai \\
\hline 3 & $\begin{array}{l}\text { Masukkan salah satu isi dari } \\
\text { informasi anggota di form, } \\
\text { lalu klik tombol "HAPUS" }\end{array}$ & $\begin{array}{l}\text { Sistem akan memberikan pesan "Data Berhasil } \\
\text { Dihapus" }\end{array}$ & Sesuai \\
\hline 4 & $\begin{array}{l}\text { Klik tombol "BATAL" pada } \\
\text { form data Bangku }\end{array}$ & Sistem akan menghapus semua isi di di kolom. & Sesuai \\
\hline 5 & $\begin{array}{l}\text { Masukkan No. Pesan atau } \\
\text { No. Anggota pada kolom } \\
\text { cari, lalu klik "Cari" untuk } \\
\text { mencari data }\end{array}$ & $\begin{array}{l}\text { Sistem akan menampilkan data yang dicari di } \\
\text { tabel, namun jika data tidak ada maka sistem akan } \\
\text { memberi pesan "Data yang Anda cari Tidak dapat } \\
\text { Ditemukan" }\end{array}$ & Sesuai \\
\hline 6 & $\begin{array}{l}\text { Klik tombol "Keluar" pada } \\
\text { form data Bangku }\end{array}$ & \multicolumn{1}{|c|}{ Sistem akan kembali ke menu utama. } & Sesuai \\
\hline
\end{tabular}

Pada proses ini diuji segala fungsi

d. Pengujian Black Block Testing Pada Form Data Peminjaman masukan dan keluaran yang terdapat di form data peminjaman satu per satu untuk mengecek adanya kekeliruan atau tidak.

Tabel 4 Pengujian Blackbox Form Data Peminjaman

\begin{tabular}{|r|l|l|c|}
\hline No & Skenario Pengujian & Hasil Yang Diterapkan & Kesimpulan \\
\hline 1 & $\begin{array}{l}\text { Pilih kode anggota kemudian pilih } \\
\text { kode buku, lalu klik "+" untuk } \\
\text { menambah buku yang ingin di pinjam, }\end{array}$ & $\begin{array}{l}\text { Sistem tidak akan dapat menyelesaikan } \\
\text { prosesnya apabila kolom ada yang tidak } \\
\text { dipilih (kosong), maka akan data tidak akan } \\
\text { lalu pilih kode bangku (jika ada) lalu } \\
\text { masukkan kode pinjam kemudian klik } \\
\text { "SIMPAN" }\end{array}$ & $\begin{array}{l}\text { Semua mak } \\
\text { "Data Berhasil Disimpan!" }\end{array}$ \\
\hline 2 & $\begin{array}{l}\text { Masukkan salah satu isi dari informasi } \\
\text { anggota di form, lalu klik tombol } \\
\text { "HAPUS" }\end{array}$ & $\begin{array}{l}\text { Sistem akan memberikan pesan "Data telah } \\
\text { dihapus!" }\end{array}$ & Sesuai \\
\hline 3 & $\begin{array}{l}\text { Klik tombol "BATAL" pada form data } \\
\text { Peminjaman }\end{array}$ & $\begin{array}{l}\text { Sistem akan menghapus semua isi di } \\
\text { kolom. }\end{array}$ & Sesuai \\
\hline 4 & $\begin{array}{l}\text { Klik tombol "Keluar" pada form data } \\
\text { Peminjaman }\end{array}$ & Sistem akan kembali ke menu utama. & Sesuai \\
\hline
\end{tabular}


e. Pengujian Black Block Testing Pada Form Data Pengembalian
Pada proses ini diuji segala fungsi masukan dan keluaran yang terdapat di form data pengembalian satu per satu untuk mengecek adanya kekeliruan atau tidak.

Tabel 5 Pengujian Blackbox Form Data Pengembalian

\begin{tabular}{|r|l|l|c|}
\hline No & Skenario Pengujian & Hasil Yang Diterapkan & Kesimpulan \\
\hline 1 & $\begin{array}{l}\text { Masukkan kode } \\
\text { pengembalian kemudian } \\
\text { klik enter 2x pada tanggal } \\
\text { pengembalian untuk melihat } \\
\text { total denda lalu "SIMPAN" }\end{array}$ & $\begin{array}{l}\text { Sistem tidak akan dapat menyelesaikan prosesnya } \\
\text { apabila kolom ada yang tidak dipilih (kosong), } \\
\text { maka data tidak akan bisa disimpan, namun apabila } \\
\text { data terisi semua maka akan menampilkan pesan } \\
\text { "Data Berhasil Disimpan!" }\end{array}$ & Sesuai \\
\hline 2 & $\begin{array}{l}\text { Masukkan salah satu kode } \\
\text { pengembalian di form, lalu } \\
\text { klik tombol "HAPUS" }\end{array}$ & $\begin{array}{l}\text { Sistem akan memberikan pesan "Data telah } \\
\text { dihapus!" }\end{array}$ & Sesuai \\
\hline 3 & $\begin{array}{l}\text { Klik tombol "BATAL" } \\
\text { pada form data } \\
\text { Pengembalian }\end{array}$ & Sistem akan menghapus semua isi di di kolom. & Sesuai \\
\hline 4 & $\begin{array}{l}\text { Klik tombol "Keluar" pada } \\
\text { form data Pengembalian }\end{array}$ & Sistem akan kembali ke menu utama. & Sesuai \\
\hline
\end{tabular}

\section{Simpulan}

Dari penelitian yang telah dilakukan pada sistem pengolahan data perpustakaan Sekolah Eka Wijaya yang telah dijelaskan di beberapa bab sebelumnya, peneliti dapat menyimpulkan bahwa penggunaan sistem manual di perpustakaan menjadi tidak efektif dan efisien dalam menghasilkan suatu informasi dan membutuhkan banyak ruang dikarenakan banyaknya arsip dokumen setiap harinya.

Sedangkan dengan adanya sistem komputerisasi diharapkan dapat meningkatkan keefektifan serta keefisienan di perpustakaan Sekolah Eka Wijaya. Berikut beberapa keuntungan menggunakan sistem:

a. Mencegah serta meminimalisir terjadinya data yang ganda ataupun arsip yang hilang.

b. Memudahkan pembaca dalam mencari buku yang diinginkan.

c. Keteraturan dalam tempat duduk sehingga meningkatkan konsentrasi dalam membaca.

d. Meningkatkan kinerja petugas perpustakaan sehingga menjadi lebih baik.

e. Mencegah terjadinya pekerjaan yang berulang-ulang.

f. Memudahkan dalam meminjam ataupun mengembalikan buku.

g. Memudahkan petugas dalam membuat laporan.

\section{Saran}

Demi tercapainya tujuan dan sasaran yang diharaapkan dari sistem ini, maka berikut beberapa saran yang diberikan penulis agar kedepannya sistem ini lebih optimal, berikut beberapa diantaranya:

a. Dibagian penghapusan data, data tidak bisa dipilih langsung jadi, diharapkan ketelitian dalam mengetik data yang ingin dihapus. Begitu pula jika ingin memperbaharui data.

b. Dalam peminjaman buku, murid perlu mendaftar di data anggota pada sistem ini, diharapkan kedepannya tidak perlu lagi mendaftar anggota namun hanya menggunakan kartu siswa untuk discan.

c. Dalam meminjam buku langsung, murid harus mencari buku yang mereka ingin lalu mengingat kode buku tersebut, sebaiknya kedepannya sistem disediakan scan ISBN yang membuat buku itu langsung masuk kedaftar buku yang dipinjam.

d. Dalam membooking bangku, diharapkan kedepannya bangku yang tersedia dapat dibooking dengan gambaran visual dari letak bangku itu sendiri(seperti sistem bioskop) sehingga bangku dapat terlihat jelas mana yang belum terisi mana yang sudah terisi.

\section{Referensi}

Cahyaningtyas, Siska Iriyani, R. (2015). Perancangan Sistem Informasi Perpustakaan 
Pada SMP Negeri 3 Tulakan, Kecamatan Tulakan, Kabupaten Pacitan. Indonesian Journal on Networking and Security, IV.

Muhamad Muslihudin, O. (2016). Analisis dan Perancangan Sistem Informasi Menggunakan Model Terstruktur dan UML. Penerbit Andi.

Munir, R. (2011). Algoritma \& Pemrograman. Informatika Bandung.

Nur, R. A. A. . (2019). Rancangan Sistem Aplikasi Perpustakaan di SMP Budi Utomo (Pelayanan Mandiri, Feedback dan Resensi). Universitas Indraprasta PGRI.

Setiawan, H. S. (2017). Program Aplikasi Perpustakaan Menggunakan Java Netbeans 8.9.2 dan Catalogue Online dengan Database MySQL. Jurnal Informatika Terpadu, III.

Sutabri, T. (2012). Analisis Sistem Informasi. Penerbit Andi.

Syarip, M. (2017). Sistem Informasi Peminjaman Buku di Madrasah Tsanawiyah Nurul Huda Dengan Aplikasi Java Netbeans. Universitas Indraprasta PGRI.

Tim Dosen. (2012a). Pemrograman. Unindra Press.

Tim Dosen. (2012b). Sistem Basis Data. Unindra Press.

Widianti, U. D. (2012). Pembangunan Sistem Informasi Aset di PT. Industri Telekomunikasi Indonesia. Jurnal Ilmiah Komputer Dan Informatika (KOMPUTA), I.

Yoga, Hieronimus Hardian, M. (2019). Analisis dan Perancangan Sistem Informasi Perpustakaan Dengan Teknologi Java dan MySQL Studi Kasus SMA SANTA MARIA 3 CIMAHI. Naratif (Journal Ilmiah Nasional Riset Aplikasi Dan Teknik Informatika), I. 